\title{
Explaining the Failure to Insure Catastrophic Risks
}

\section{Carolyn Kousky and Roger Cooke}

Resources for the Future, 1616 P Street NW, Washington DC 20036, U.S.A.

E-mails: kousky@rff.org; cooke@rff.org

It has often been observed that homeowners fail to purchase disaster insurance. Explanations have ranged from behavioural biases to information search costs. We show that the decision to forego disaster insurance may be quite rational. Solvency-constrained insurers are required to have access to enough capital to cover a particular percentile of their aggregate loss distribution. When insuring risks with loss distributions characterised by fat tails, micro-correlations or tail dependence, insurers need to charge a price that is many times the expected loss in order to meet their solvency constraint. Homeowners, facing a budget constraint and a constraint that their utility with insurance exceeds that without it, may find the required loadings too high to make insurance purchase an optimal decision.

The Geneva Papers (2012) 37, 206-227. doi:10.1057/gpp.2012.14

Keywords: catastrophe; insurance; fat tails; dependence

\section{Introduction}

It has often been observed that individuals fail to purchase disaster insurance, even when offered at rates that are subsidised or appear well within the range that a consumer would pay given reasonable levels of risk aversion. ${ }^{1}$ This observation is frequently explained with reference to behavioural heuristics or biases that prevent individuals from making rational decisions about low-probability, high-consequence events. $^{2}$ These biases, or lack of information, could make individuals' perceived risk differ from the actual risk. ${ }^{3}$ A related explanation that has been given is based on bounded rationality: individuals have limited information on loss probabilities and improving their information involves transaction costs that they may not believe are worth incurring. ${ }^{4}$

While all these factors play a role in the demand for insurance, we show in this paper that the failure to purchase insurance for catastrophic risks could also be rational - that is, insurance purchase may not be optimal for catastrophic risks even when individuals have perfect information about the risk and are not subject to any biases when evaluating low-probability risks. By "catastrophic risks", we mean those characterised by occasional severe losses and also by dependence. In particular, we focus on three characteristics of loss distributions: fat tails, micro-correlations and

\footnotetext{
${ }^{1}$ For example, Palm (1995), Dixon et al. (2006), Powell (2006).

${ }^{2}$ For example, Johnson et al. (1993).

${ }^{3}$ Kunreuther (1996).

${ }^{4}$ Kunreuther and Pauly (2004).
} 
tail dependence. ${ }^{5}$ With fat-tailed loss distributions, the probability of ever larger damages decreases more slowly than for thin-tailed distributions to which we are accustomed. Micro-correlations are small, positive, average correlations between risks that can have a large impact if such risks are aggregated. Tail dependence refers to the tendency of extreme losses to occur together. These three characteristics of catastrophic risks all combine to create, with low probability, the potential for enormous losses.

Insurers are often managed to meet solvency constraints. This means they must have access to enough capital to meet a certain level of loss, say the 99th percentile of the insurer's total loss distribution. This solvency constraint may be determined by regulation, rating agencies or internal firm decisions. For catastrophic risks, firms face an inter-temporal smoothing problem of trying to match regular premium payments, insufficient in any given year to cover a large loss, with the need for enormous sums of capital in the catastrophic years. ${ }^{6}$ This need to access a large amount of capital to cover a catastrophic loss drives up premiums. We show here that, in fact, the premium could be so high that it would not be rational for a consumer to purchase the policy.

The next section of the paper discusses the particular aspects of catastrophic losses that we are considering in this paper. The subsequent section presents our model of the property insurance market and the homeowner's insurance decision, along with our main findings. The penultimate section discusses policy implications and the final section concludes.

\section{The nature of catastrophes}

Risks that people colloquially term "catastrophic" are usually characterised by fat tails and dependence. With fat-tailed loss distributions, the probability of an event declines slowly, relative to its severity. Simply, very large losses are possible. The precise mathematical definition of fat tails is rather subtle, ${ }^{7}$ but a working notion is that damage variable $X$ has a fat tail if, for sufficiently large values $x$, the probability that $X$ exceeds $x$ is $k x^{-\alpha}$, for some constants $\alpha, k>0$. The variable $\alpha$ is referred to as the tail index and it roughly governs how fat the tail of the distribution will be. ${ }^{8}$ Many natural catastrophes, from earthquakes to wildfires, have been shown to be fat tailed. ${ }^{9}$

Catastrophic risks are also dependent and this dependence can take a number of forms. First, catastrophic risks tend to be spatially correlated. When a disaster hits a region, a large number of structures are all affected simultaneously. In practice, this correlation declines with the spatial distance between policies. When it declines to zero, it allows insurers to diversify by holding policies in different regions. Unfortunately, "close to zero" does not count as zero for diversification benefits. Even small, positive, average correlations among policies, which we term micro-correlations, can cause problems when

\footnotetext{
${ }^{5}$ Cooke and Kousky (2010).

${ }^{6}$ Jaffee and Russell (1997).

${ }^{7}$ Resnick (2007).

${ }^{8}$ For more on the technical details of fat-tailed distributions, see Cooke and Nieboer (2011).

${ }^{9}$ For example, Schoenberg et al. (2003), Newman (2005), Holmes et al. (2008).
} 
risks are aggregated. This is because the correlation between aggregations of weakly correlated variables balloons. ${ }^{10}$ Thus, for example, if losses across lines of business are weakly correlated, the correlation between portfolios of such policies could be large.

Catastrophes, when they occur, also often impact multiple lines of business for an insurer - for example, homes may be damaged, cars may be damaged and businesses may be hurt, all simultaneously. This can introduce another type of dependence: tail dependence. Tail dependence refers to the probability that one variable exceeds a certain percentile, given that another has also exceeded that percentile. More simply, it means bad things are more likely to happen together. This has been observed for lines of insurance covering over 700 storm events in France. ${ }^{11}$ Different types of damages can also be tail dependent, such as wind and water damage, ${ }^{5}$ or earthquake and fire damage. We show here that when insurers hold a portfolio where the loss distribution is characterised by any of these three phenomena, it requires a solvency-constrained insurer to have access to a large sum of capital that in turn necessitates loadings that may be beyond what a consumer is willing to pay.

\section{The Model}

The optimisation problem of a solvency-constrained insurer can be modelled as follows. They hold policies indexed by $i$, across lines of business indexed by $j$, and regions indexed by $s$, where $\alpha$ denotes the coverage level chosen by the policyholder. Let $\alpha=\sum \sum \sum \alpha_{i j s}$ be the portfolio of policies - the total exposure-held by the insurer. Let total claims in one year for the insurance company be given by $C_{\alpha}=\sum \sum \sum c_{i j s}$. An insurer has access to some level of assets to support losses, given by $A$, and may also purchase reinsurance, $K$, at cost $r$ per dollar covered. ${ }^{12}$ We ignore marketing and transaction expenses here, although obviously prices will need to be high enough to cover these costs, as well as to provide a fair rate of return on equity (while these are important considerations, we suppress them here to focus attention on the impact of the loss distribution on pricing). For a solvency-constrained insurer, the firm cannot spend more on claims in a given year than the sum of total yearly revenue (with the price of insurance per dollar coverage given by $q$, total revenue is $\sum \sum \sum q_{j s} \alpha_{i j s}$ ), assets and reinsurance. Following Kleindorfer and Klein, ${ }^{13}$ expected profits for the insurer, $E\left[\Pi\left(q_{j s}, A, K\right)\right]$, are thus given by:

$$
\begin{aligned}
E\left[\Pi\left(q_{j s}, A, K\right)\right]= & \sum \sum \sum q_{j s} \alpha_{i j s}-r K \\
& -E\left[\operatorname{Min}\left(C_{\alpha}, \sum \sum \sum q_{j s} \alpha_{i j s}+(1-r) K+A\right)\right] .
\end{aligned}
$$

\footnotetext{
${ }^{10}$ This is seen by calculating the correlation between two portfolios of $N$ policies, with the average covariance between the individual policies given by $c$ and the average variance give by $\sigma^{2}=\left(N^{2} \cdot c\right) /$ $\left(N \sigma^{2}+N(N-1) c\right)$. This goes to 1 as $N \rightarrow \infty$.

${ }^{11}$ Lescourret and Robert (2006).

12 This is, of course, a very simplified construction of reinsurance. For alternate forms of reinsurance, see Ladoucette and Teugels (2006).

${ }^{13}$ Kleindorfer and Klein (2002).
} 
The insurer manages aggregate risk to keep the probability of insolvency below some target level $\lambda{ }^{14} F(C \alpha)$ is the cumulative distribution function of claims an insurer faces for a given portfolio. The insurer will then maximise expected profits subject to the following constraint:

$$
\operatorname{Pr}\left(C_{\alpha}>\sum \sum \sum q_{j s} \alpha_{i j s}+(1-r) K+A\right) \leqslant \lambda
$$

Define $S_{\alpha, \lambda}$ to be the required capital, or surplus, the insurer must have to cover claims that will occur with probability $1-\lambda$ when holding a given portfolio $\alpha$. Then:

$$
F^{-1}(1-\lambda)=S_{\alpha, \lambda}
$$

If the loss distributions of the lines or policies in the portfolio are characterised by fat tails or dependence, more surplus will be required than if they were thin-tailed and independent, since the upper quantiles of the inverse of the aggregate claims distribution $\left(F^{-1}\right)$ increase in the presence of fat tails and dependencies. This can be seen in numerical simulations.

\section{Simulating required surplus and the impacts on pricing}

We simulate an insurer's portfolio when holding risks characterised by dependence and/or fat tails. To do this, we loosely base the loss distribution on the distribution of yearly flood insurance claims in Broward County, Florida. These claims are roughly lognormally distributed, with a ratio between the median and the $95^{\text {th }}$ percentile of 7 . We standardise the median to 1; the mean is then 2. First, consider an insurer holding 100 independent policies, all with this same loss distribution. The grey curve in Figure 1a depicts the required surplus for a given percentile. The sum of independent variables is nearly normal with a 99th percentile of 302. This means that for an insurer managing its portfolio to keep the probability of insolvency below 0.01 , they must charge $1.51(302 / 200)$ times the expected loss per policy (discussed further below) to have sufficient capital (the scale of losses here is irrelevant as what we are ultimately concerned about is the relative amount of required surplus to expected loss).

Now consider what happens to the required surplus when the policies have a small, average, positive correlation of 0.04 . We chose this value - although any small positive correlation would produce a similar result - because it was found that flood insurance claims in the U.S. at a county level had this average correlation. ${ }^{5}$ This pair-wise correlation among 100 variables is shown in the black curve in Figure 1a. With these positive, global correlations, the mean is unaffected, but the 99th percentile is now 434 . The insurer needs more capital than when policies were independent and now must charge 2.17 (434/200) times the expected loss to guard against the 1-in-100 year event.

\footnotetext{
${ }^{14}$ Here, this probability is taken to be exogenous, perhaps set by capital regulations. For instance, in the European Union, beginning in 2012, insurance companies will be regulated through the Solvency II regulations. The Solvency Capital Requirement component of the regulations takes a Value-at-Risk approach, whereby an insurer must keep the probability of insolvency below a certain level, currently set at 0.5 per cent.
} 

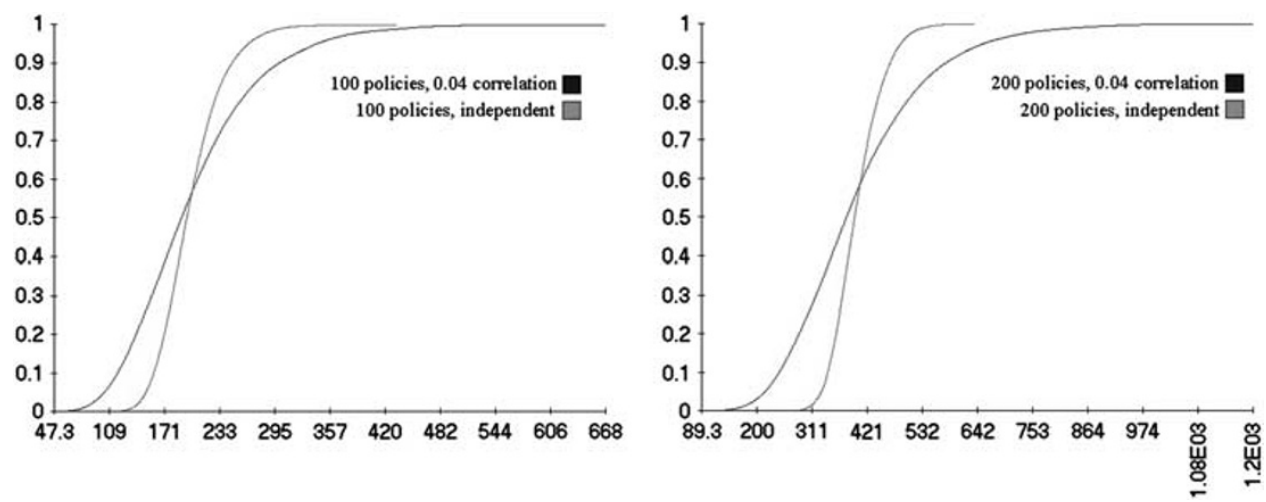

Figure 1. Cumulative distribution functions for sums of 100 (a) and 200 (b) independent and microcorrelated lognormal variables.

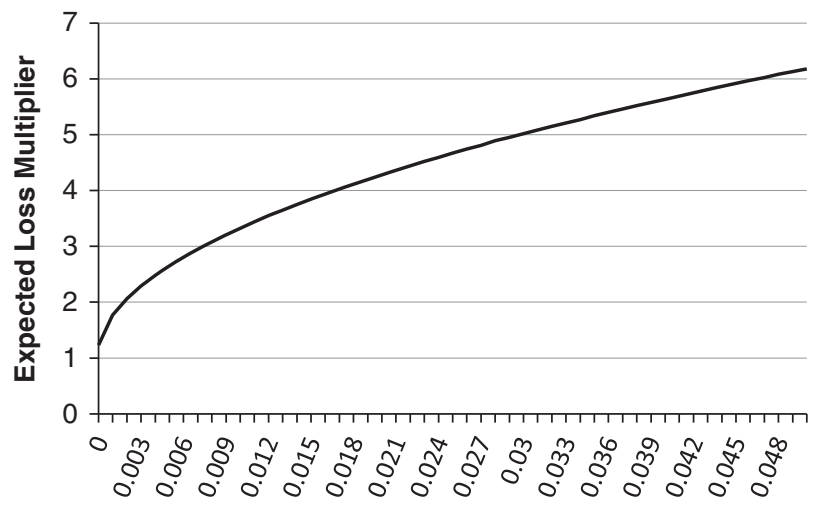

Average Correlation Between Policies

Figure 2. Required multiplier for micro-correlated portfolio of 10,000 normal variables.

To show how quickly tiny, positive correlations between policies can become pernicious, consider Figure 2. In this figure, we simulate a portfolio of 10,000 policies, each with a yearly 0.01 probability of a 10,000 unit loss occurring and a 0.99 probability of no loss. We again assume the insurer requires capital equivalent to the 99th percentile of the aggregate loss distribution. The horizontal axis shows the average correlation among policies, increasing from 0 to $0.05 .{ }^{15}$ The vertical axis shows the multiplier of the expected damages that the insurer must charge (in this simplified simulation) to achieve the necessary level of capital. As the graph shows, the multiplier increases fairly quickly for only small increases in the average correlation.

${ }^{15}$ Note that for the correlation of groups of counties, to be, say, 0.04, as used earlier, the correlation between the individual policies must be much lower. 


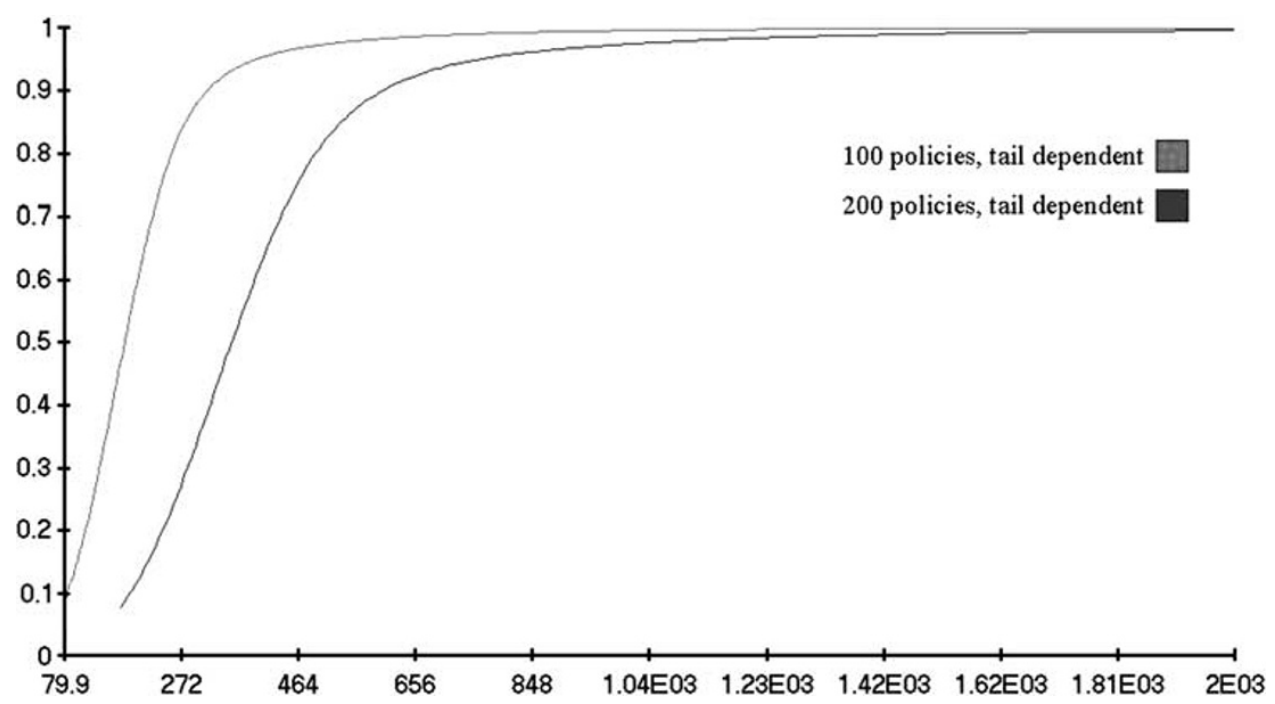

Figure 3. Cumulative distribution functions for sums of 100 and 200 micro-correlated and tail-dependent lognormal variables.

When policies are independent, expanding an insurer's portfolio can help reduce the amount of capital they need to hold. Consider an insurer holding just one policy, again roughly corresponding to Broward County, as mentioned above. With an expected loss of 2, in order to cover the 1-in-100 loss event, the insurer would require 14.8 units of capital, which is the 99th percentile of the lognormal distribution. That would require charging $7.4(14.8 / 2)$ times the expected loss. In other words, neglecting profit and transaction costs, the insurer would have to charge 7.4 times the actuarial fair price to meet their capital requirements. If the insurer can sell 100 similar policies, and if the claims from these policies are independent, then the expected loss from all 100 policies is 200 , and the capital requirement is 302 , giving a multiplier of $1.51(302 / 200)$. This demonstrates the benefit of pooling the risks of these 100 policies; indeed, this is what makes insurance possible. The grey curve in Figure 1b shows the benefits of further aggregation. This is the same simulation as the grey curve in Figure 1a, except for 200 variables, as opposed to 100 . Here, the 99th percentile is 534, requiring the insurer to charge $1.34(534 / 400)$ times the expected loss, less than when they only held 100 policies.

These benefits of aggregation can also be obtained, although to a lesser degree, when policies are micro-correlated. The black curve in Figure 1b shows 200 policies with the 0.04 mutual correlation. Now, to cover the 99 th percentile, the insurer needs 840 units of capital, requiring a fair price multiplier of 2.10 (840/400), again, less than with 100 policies (2.17), but not as much of a decline in price as when the policies were independent. 

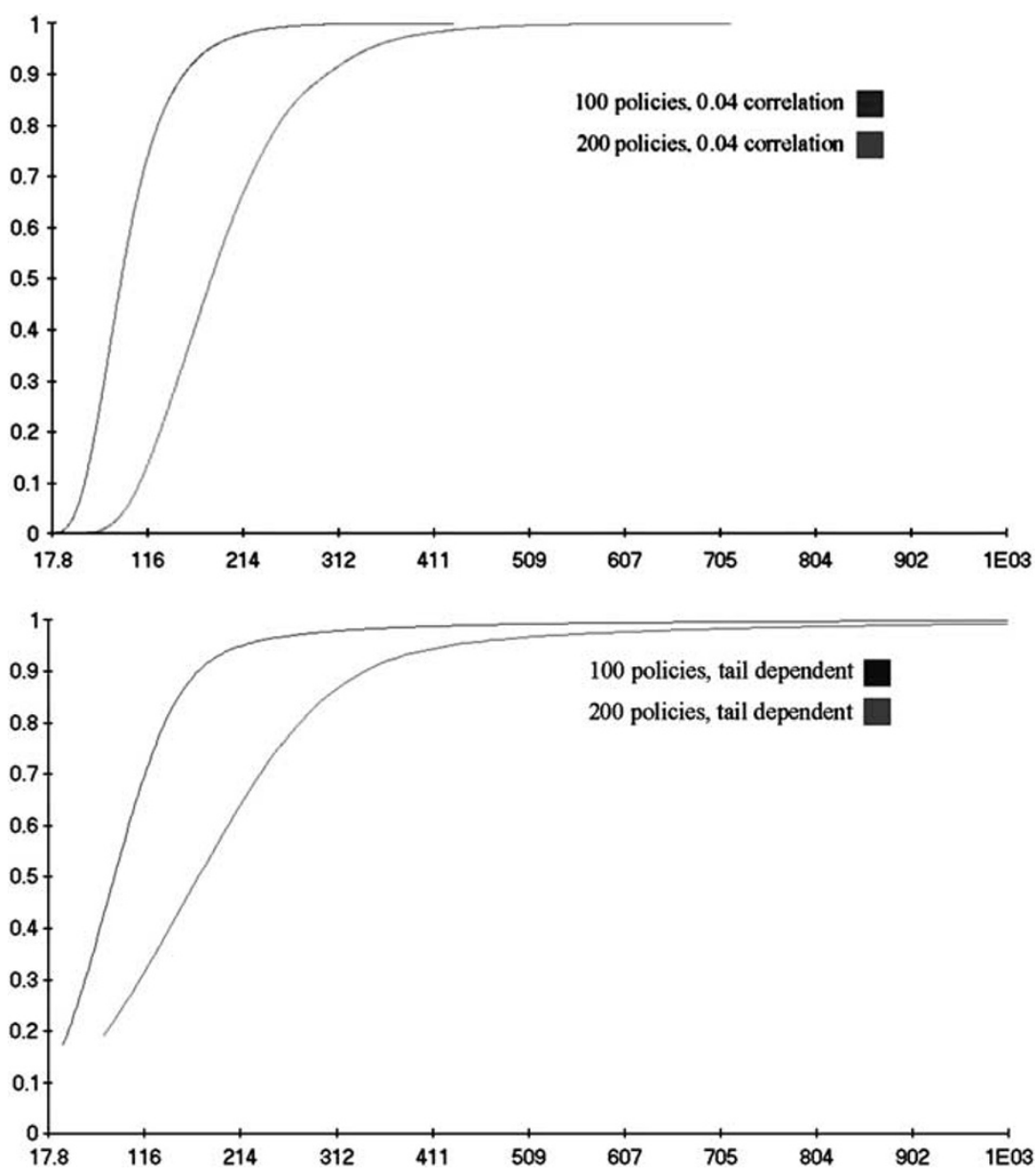

Figure 4. Cumulative distribution functions for sums of 100 and 200 micro-correlated (a) and taildependent (b) Pareto (2) variables.

We next consider the impact of tail dependence. Tail dependence can be imposed on variables by using copulas. Copulas were developed to separate the effect of dependence from the effect of marginal distributions; a copula is a distribution on the unit square with uniform marginal distributions. ${ }^{16}$ The previous simulations used the normal copula, which has no tail dependence. Figure 3 shows the cumulative distribution functions for sums of 100 and 200 lognormal variables with the same micro-correlation of 0.04 , but now joined with the tail dependent Gumbel copula. The $99^{\text {th }}$ percentiles are now 737 and 1,480, respectively. This requires fair

\footnotetext{
${ }^{16}$ For more on copulas and dependence modelling, see: Nelson (1999), Kurowicka and Cooke (2006), and Kurowicka and Joe (2011).
} 
Table 1 Expected loss multipliers required to meet the 0.01 solvency constraint

\begin{tabular}{lcc}
\hline & Sum of 100 & Sum of 200 \\
\hline Lognormal (standard deviation $=3.5$, mean $=2)$ & & \\
$\quad$ Independent & 1.51 & 1.34 \\
Correlated (0.04), no tail dependence & 2.17 & 2.10 \\
Correlated (0.04), tail dependence & 3.7 & 3.7 \\
& & \\
Pareto (tail index $=2$, mean $=1$ ) & 1.77 & 1.49 \\
Independent & 2.45 & 2.31 \\
Correlated (0.04), no tail dependence & 4.43 & 8.69 \\
Correlated (0.04), tail dependence & & \\
\hline
\end{tabular}

price multipliers of $3.7(737 / 200)$ and $3.7(1,480 / 400)$. The additional pooling of holding 200 policies, as opposed to 100 policies, has no effect at all on the required price in the presence of tail dependence. The distribution functions are also decidedly less normal.

Finally, we consider the impact of fat-tailed loss distributions on required surplus. In Figure 4a, the individual variables are assigned a fat-tailed Pareto distribution with mean 1 and a tail index of 2, indicative of infinite variance - a very fat tail. If these policies are independent (not shown in a figure), then for 100, the required fair price multiplier is 1.77 (recall the mean of these policies is now 1). For 200 policies, the required multiplier drops slightly to 1.49 , thus, again, aggregation can help reduce the required costs. These benefits of aggregation still accrue when the fat-tailed variables are micro-correlated, but not as strongly. Figure 4a shows the same Pareto variables with a micro-correlation of 0.04 but without tail dependence. Here, the multiplier for 100 policies is 2.45 and for 200 policies, it is 2.31 . These benefits of aggregation disappear, however, when the insurer is faced with policies that are both fat-tailed and tail dependent. When the micro-correlations are realised with the Gumbel copula, shown in Figure 4b, the multipliers for sums of 100 and 200 variables are 4.34 and 8.69 , respectively. In this case, aggregation actually makes things worse for the insurer.

The required multipliers for sums of 100 policies are summarised in Table 1. These simple simulation results are not out of line with empirical research on this topic. A study undertaken by Wharton's Risk Management and Decision Processes Center found that premiums for insuring large-scale disasters can be five to ten times higher than the expected loss. ${ }^{17}$ It is important to keep in mind that this finding was for highly concentrated insurers in Florida and thus is not broadly applicable, but is an example of insurance for a catastrophic risk.

Table 1 clearly shows how fat-tailed or dependent loss distributions can be more expensive to insure than non-catastrophic risks. It also shows some interesting findings regarding the benefits of aggregation. When aggregating independent policies, the

\footnotetext{
${ }^{17}$ Kunreuther et al. (2009).
} 
multiplier always decreases. For lognormal policies, it decreases when aggregating micro-correlated, tail-independent policies, but only slightly; the benefits of aggregation are not as strong. All benefits of aggregation are lost when the policies are tail dependent. When facing policies that are fat tailed (simulated here as Pareto variables), ${ }^{18}$ there is still some benefit to aggregation, but if the policies are fat tailed and tail dependent, aggregation actually requires an increase in price. This latter finding has been explored by Ibragimov et al. ${ }^{19}$

\section{Impact of higher multipliers on demand}

In the case of catastrophic insurance lines, maintaining the same solvency probability thus means increasing premiums, either to raise capital directly to meet the surplus requirement or to finance the purchase of reinsurance. Two potential difficulties emerge. First, regulators may limit the price of insurance. It has been noted by insurance scholars that state insurance commissioners in the U.S. - who have the power to regulate premiums - tend to weight low prices and availability of policies more heavily than solvency considerations or management of catastrophe risk. ${ }^{20}$ If insurers cannot charge prices that they feel are sustainable, they will leave the market. ${ }^{21}$ This creates the need for so-called residual market mechanisms. These are programmes set up by states to provide insurance policies to those people who cannot find a policy in the voluntary market. ${ }^{22}$ Some residual market mechanisms have underpriced insurance, perhaps out of ignorance of the fat-tailed or dependent nature of a risk, due to a lack of foresight, or from political pressure, creating enormous exposures for some states.

Second, and more problematically for insurance markets, even if the price of insurance is not capped by regulators, homeowners might not be willing to pay the higher premiums required for catastrophic and dependent lines. Consider $i=1, \ldots, N$ policyholders in a given region or line of business. We focus on a homeowner's decision. Each year homeowner $i$ faces a potential loss of $L_{i}$. An insurer offers coverage to homeowners at a rate of $q$ per dollar of coverage (rates may vary across lines or regions, but individual-specific rates are not possible). The basic theoretical model of an individual's decision to purchase insurance ${ }^{23}$ is formalised in most microeconomics and decision analysis textbooks. Adapted to our current set-up, let $p$ be the yearly probability of disaster for each individual, let $w_{i}$ be the individual's total

\footnotetext{
${ }^{18}$ In fact, the Pareto variables used in the simulation here have infinite variance. Though the empirical variance and correlations are defined in every sample, their theoretical values are infinite and this means that the empirical values are unstable. The micro-correlations are realised with rank correlations and are always finite, but all second moment properties of these distributions are unstable. Hence the numbers for the Pareto (2) variables may change substantially when simulations are repeated with other random seeds.

19 Ibragimov et al. (2009).

${ }^{20}$ Klein and Wang (2007).

${ }^{21}$ Klein (2005).

${ }^{22}$ See Kousky (2011).

${ }^{23}$ For example, Mossin (1968).
} 
wealth, let $q$ be the price per dollar of coverage and let $\alpha_{i}$ be the amount of dollars of insurance coverage purchased. The expected utility (EU) for a potential consumer of insurance is then given by:

$$
E U=(1-p) \cdot u\left(w_{i}-a_{i} \cdot q\right)+p \cdot u\left(w_{i}-a_{i} \cdot q-L_{i}+a_{i}\right)
$$

A risk-averse homeowner chooses $\alpha$ by maximising expected utility (subject to the constraint that $\alpha_{i} \geqslant 0$ ), giving the first-order condition (where $\alpha^{*}$ is the optimal amount of insurance purchased $)^{24}$ :

$$
\begin{aligned}
& -q \cdot(1-p) \cdot u^{\prime}\left(w_{i}-a_{i} \cdot q\right) \\
& +p \cdot(1-q) \cdot u^{\prime}\left(w_{i}-a_{i} \cdot q-L_{i}+\alpha_{i}^{*}\right)=0 .
\end{aligned}
$$

Assume insurance is priced actuarially fairly (ignoring transaction and marketing costs), such that $p=q$. In this case, we get the well-known result that a risk-averse consumer, facing actuarial rates, will fully insure: $\alpha_{i}^{*}=L_{i}$.

To get a first-order estimate of the impact of the price of catastrophe insurance on demand, assume the homeowner's utility follows the common constant relative risk aversion function, with $w$ indicating wealth (and now suppressing the subscript $i$ ):

$$
U=\frac{w^{1-\eta}}{1-\eta} \quad \text { if } \eta \neq 1
$$

and

$$
U=\ln (w) \quad \text { if } \eta=1 .
$$

The parameter $\eta$ is the coefficient of relative risk aversion. It governs the curvature of the utility function, and gives an indication of aversion to risk. Higher values for $\eta$ indicate higher levels of risk aversion.

Insurance is not an all or nothing decision. The homeowner can choose to partially insure and when $q>p$, from Eq. (8), a risk-averse homeowner will choose $\alpha^{*}<L$. ${ }^{25}$ For simplicity, however, we assume that the homeowner chooses $\alpha^{*}=L$, and that the loss is equal to the value of their home. We relax this assumption below. The homeowner faces two constraints. The first is that utility with insurance must be greater than utility without insurance or:

$$
U(w-L \cdot q) \geqslant(1-p) \cdot U(w)+p \cdot U(w-L) .
$$

Note that, when the homeowner fully insurers, their total wealth is the same with or without a disaster, since loss is fully compensated by the insurance company. Let $q=x^{*} p$. This allows us to focus on $x$, or the multiple of the actuarial fair price that a

\footnotetext{
${ }^{24}$ This equation holds with equality for risk-averse consumers since, in that case, $u^{\prime}(w-L)>u^{\prime}(w)$.

${ }^{25}$ This can be seen by rearranging the first-order condition in Eq. (9) to give: $u^{\prime}\left(w-\alpha_{i, s}^{*} q_{s}\right)=\left[p_{s}\left(1-q_{s}\right) /\right.$ $\left.q_{s}\left(1-p_{s}\right)\right] u^{\prime}\left(w-\alpha_{i, s} q_{s}-L_{i}+\alpha_{i, s}\right)$. For $q_{s}>p_{s}$, the term in the brackets on the right-hand side of the equation is less than 1. This implies that $u^{\prime}\left(w-\alpha_{i, s} q_{s}-L_{i}+\alpha_{i, s}\right)>u^{\prime}\left(w-\alpha_{i, s}^{*} q_{s}\right)$. Since for a risk-averse consumer, $u^{\prime}$ is decreasing in wealth, we have: $w-\alpha_{i, s} q_{s}-L_{i}+\alpha_{i, s}<w-\alpha_{i, s}^{*} q_{s} \rightarrow \alpha_{i, s}^{*}<L$.
} 
homeowner would be willing to pay for insurance. Also, set $w=1$ and let $L$ thus be the fraction of wealth that the homeowner's home represents, which we assume is the same as the fraction of wealth at risk. Making these substitutions and solving for $x$ gives what we term the utility constraint. For $\eta=1$, this is ${ }^{26}$ :

$$
x \leqslant \frac{1-(1-L)^{p}}{L \cdot p} .
$$

And for $\eta=2$, this is:

$$
x \leqslant \frac{1}{L \cdot p}-\frac{(1-L)}{L \cdot p \cdot(p+(1-p) \cdot(1-L))} .
$$

Second, the owner cannot spend more on insurance than their disposable wealth, which is simply their total wealth, $w$, minus the value of their home, which is equivalent to the potential loss they face. Again, set $q=x p$ and $w=1$. Then, their budget constraint is given by:

$$
L \cdot x \cdot p \leqslant 1-L
$$

Solving for $x$ gives:

$$
x \leqslant \frac{(1-L)}{L \cdot p} .
$$

This budget constraint is binding only if all disposable income is spent on insurance, which, of course, is unrealistic. To avoid model complexity, we leave the constraint in the above form. A numeraire good could be added to the model to account for other purchases; this would have the effect of decreasing the amount of income available for purchasing insurance. As seen in the figures below, when homeowners have lower wealth, they are more likely to purchase affordable insurance; however, if they have more income apart from the asset of their home, they will have a lower percentage of their wealth at risk, and they will have more funds to spend on insurance. Previous theoretical work has shown the role of changes in income to be ambiguous. Holding all else constant, an increase in an individual's wealth will have no effect on demand if insurance is actuarially fair, such that $p=q$. We are examining, however, the high positive loadings associated with catastrophe coverage. In such cases, whether increases in income lead to more or less demand for insurance depends on whether an increase in income increases losses and on whether the consumer has increasing or decreasing absolute risk aversion. ${ }^{27}$ Insurance could be an inferior good if risk

\footnotetext{
${ }^{26}$ Note that if $L_{i}=0$, then this expression is undefined. Using L'Hôpital's Rule, the limit of this expression as the loss approaches zero is 1 . This makes intuitive sense. As the loss gets smaller and smaller, homeowners will be willing to pay less and less above the expected loss. At the limit, $x$ goes to 1 , indicating an unwillingness to pay more than the expected loss (it just so happens that at a loss of zero, the homeowner would not actually insure anyway).

${ }^{27}$ Cleeton and Zellner (1993).
} 

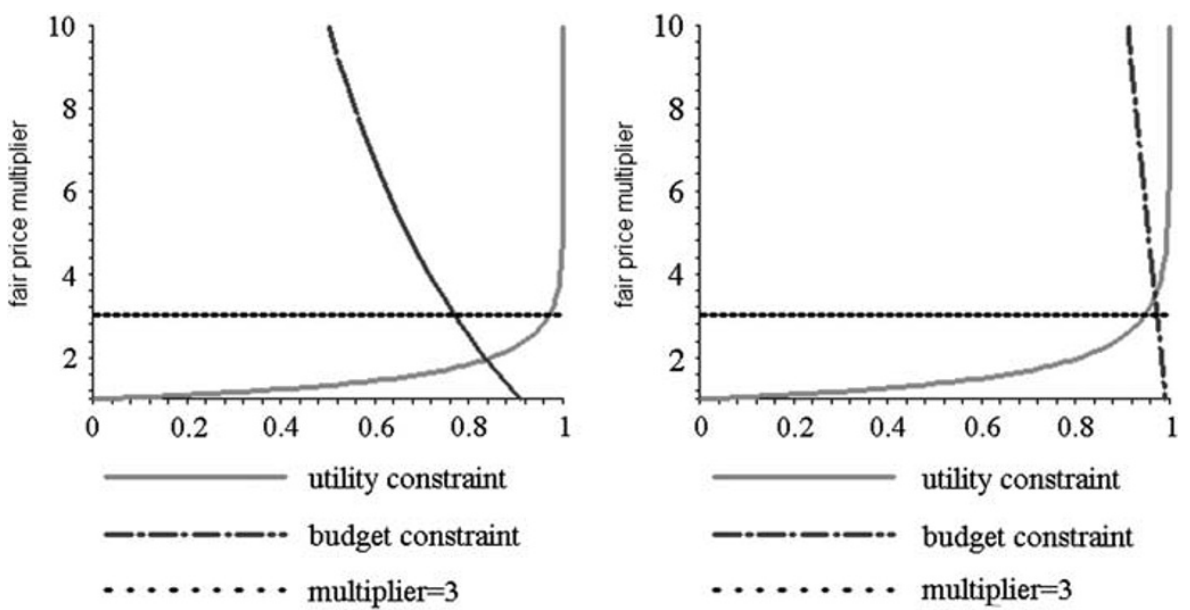

Figure 5. Homeowner budget and utility constraints $(\eta=1) ; p=0.1$ (a) and $p=0.01$ (b).

aversion decreases with wealth and the loss remains constant. ${ }^{28}$ If insurance were inferior, higher-income individuals would be observed self-insuring. An empirical estimate of the income elasticity of earthquake insurance (a catastrophic risk) found the relationship positive but relatively inelastic at $0.77 .^{29}$

For a given probability of disaster, we can plot the two constraints to determine the range of values of $x$ and $L$ for which a homeowner would insure. This is shown in Figure $5 \mathrm{a}$ for $p=0.1$ and Figure $5 \mathrm{~b}$ for $p=0.01$. A homeowner will only insure when values of $x$ (y-axis) and $L$ ( $x$-axis) are below both curves. As the probability of a disaster decreases, the income constraint relaxes, as seen in Figure 5b, since insurance is cheaper for lower probability risks for a fixed loss level. ${ }^{30}$ It is clear that insurance is not rational for most homeowners at multiplier levels that are not terribly high. A more risk-averse homeowner $(\eta=2)$ is shown in Figure 6. With greater risk aversion, the individual is willing to insure at higher multipliers. For $p=0.1$, insurance with a fair price multiplier of 3 is attractive if 76 per cent of the wealth is at risk, and for $p=0.01$, it is attractive for homeowners whose fractional wealth at risk is between 68 per cent and 96 per cent.

Figure 7 shows our constraints also as a function of $p$. For a homeowner with more wealth apart from their home, the fraction at risk will be lower and thus the budget constraint will be less binding. On the other hand, the utility constraint becomes more binding since wealthier homeowners will prefer to self-insure. Note that the low slope of the utility constraint for multipliers in the region 1 to 3 means that a small change in

\footnotetext{
${ }^{28}$ Mossin (1968) and Rees and Wambach (2008).

${ }^{29}$ Athavale and Avila (2011).

${ }^{30}$ As the probability decreases, the utility constraint shifts out very slightly. This is because even though as the probability decreases, a homeowner is willing to pay less for insurance; the graphs in Figure 5 are plotting $x$, not $q$.
} 

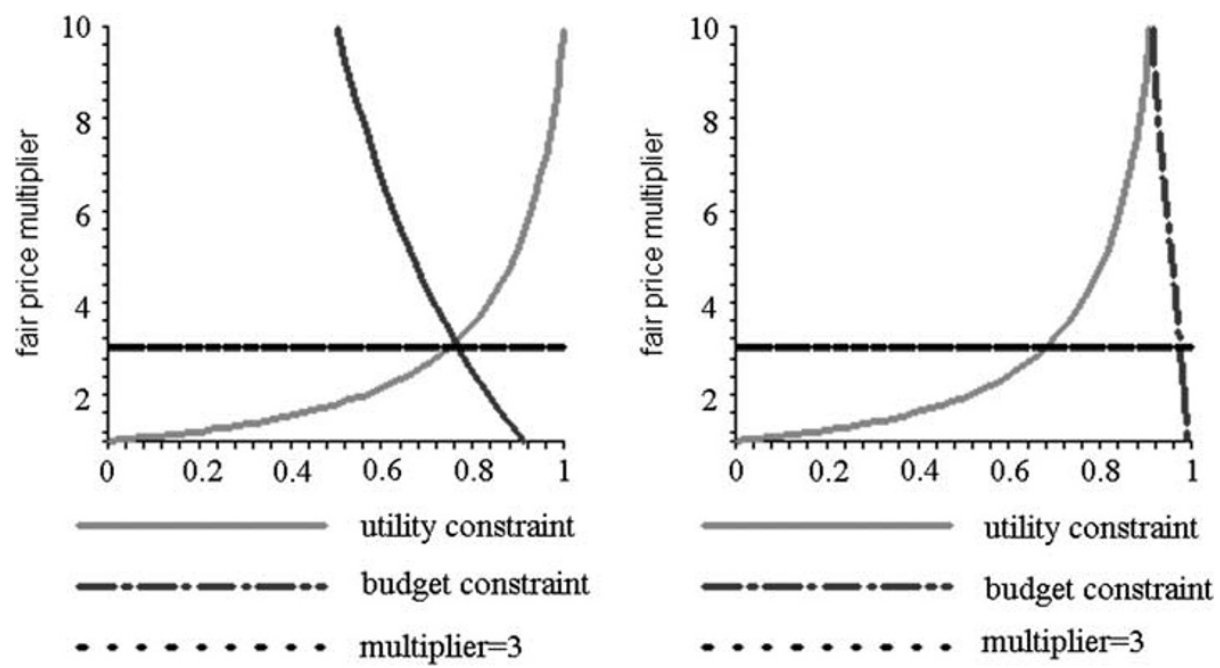

Figure 6. Homeowner budget and utility constraints $(\eta=2) ; p=0.1$ (a) and $p=0.01$ (b).

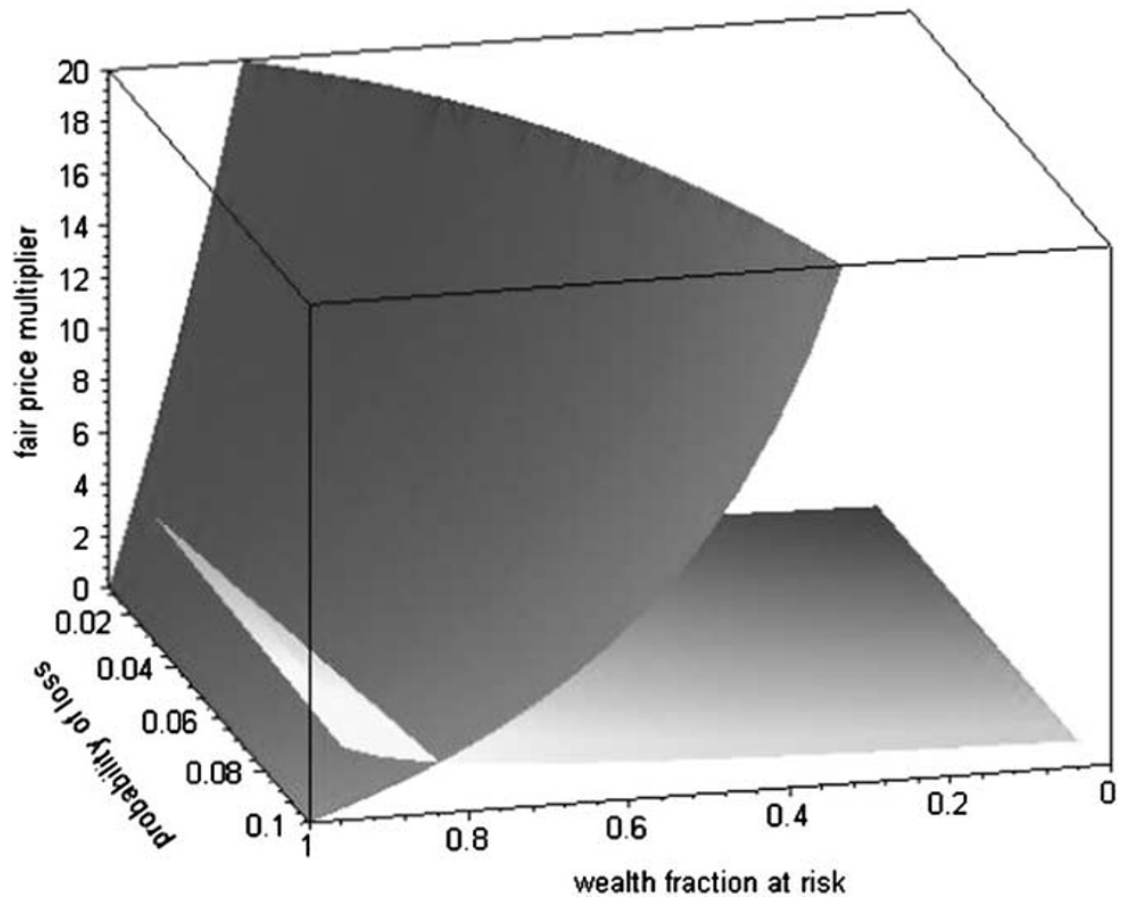

Figure 7. Homeowner budget and utility constraints as a function of wealth fraction at risk and probability of loss. 


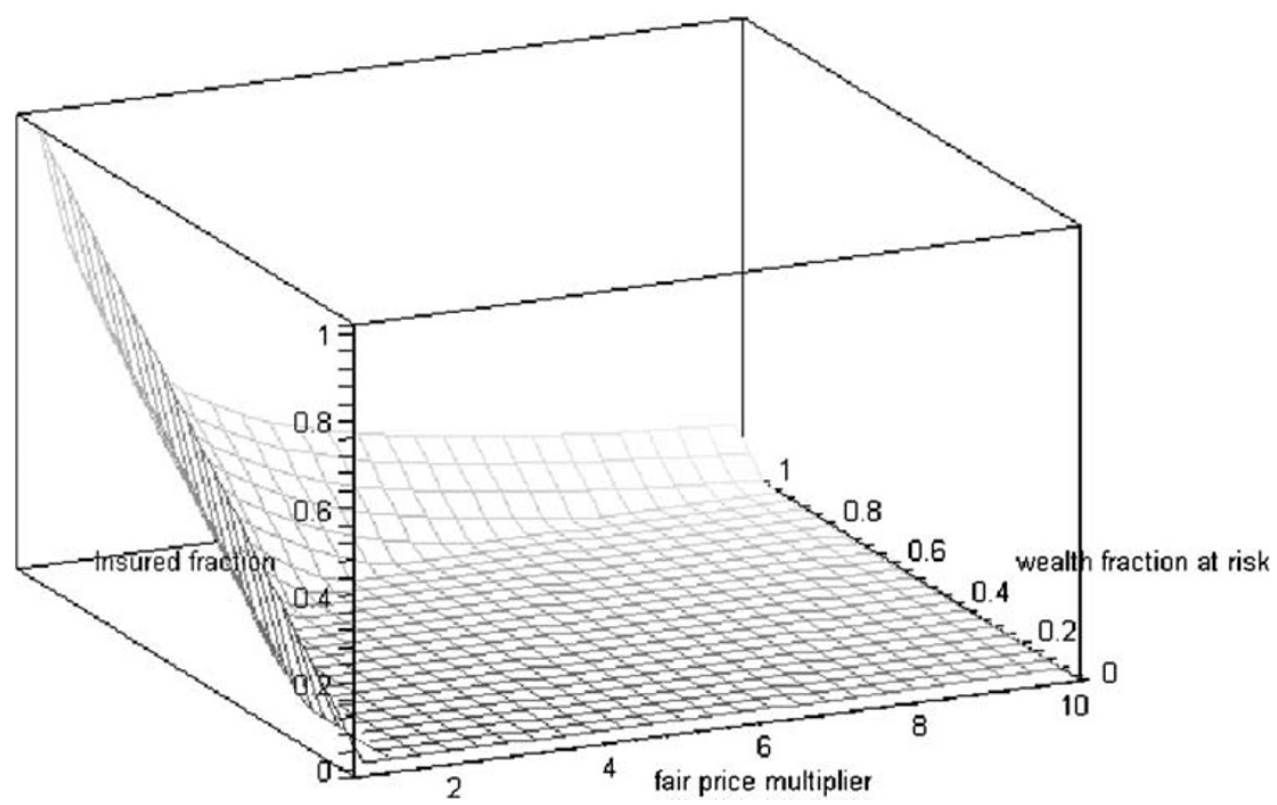

Figure 8. Optimal coverage as a function of the multiplier and wealth at risk $(\eta=1)$.

this multiplier corresponds to a large shift in fractional wealth at risk for which insurance is rational. Similar results emerge for other risk-averse utility functions.

Now, we relax the assumption that a homeowner must purchase full coverage and examine how optimal coverage levels vary with $x, p$ and $L$. In this case, for $\eta=1$ :

$$
\alpha^{*}=\frac{x p(1-L)+p(\operatorname{Lxp}-1)}{x p(x p-1)}
$$

In Figure 8, it is clear that the coverage level chosen decreases dramatically as the multiplier increases, suggesting that less than full coverage may be common for homeowners insuring catastrophic risks.

Less than full coverage can be achieved by choosing a lower coverage level or a higher deductible. Deductibles have the effect of lowering the probability of claim triggering events and lowering the fractional wealth at risk. ${ }^{31}$ Insurers may prefer higher deductibles and lower coverage levels, as well, since this can limit an insurer's total exposure or their possible loss at any percentile of the distribution. Such limitations may thus be one component of managing catastrophe risk (the role of diversification and possible policy interventions are discussed in the next section). Lower premiums would be able to be offered for lower exposure to catastrophe risk. It

\footnotetext{
${ }^{31}$ Setting total wealth equal to 1 , let $\delta$ be the expected payment for damages beneath the deductible limit, as percentage of wealth. Effective wealth becomes $1-\delta$, and effective insurable loss is $L-\delta$. Since $L<W, L /$ $W>(L-\delta) /(W-\delta)$. For claims caps the argument is similar, except that $\delta$ then denotes the expected payment for losses above the cap.
} 
is worth noting that one of the primary uses of high deductibles, however, is that they limit the need of the company to process many small claims; part of these transaction cost savings can then be passed on to the insureds in terms of lower prices for policies with high deductibles.

Figures 5-8 show that our risk-averse homeowner will not pay much more than a couple times expected loss for disaster insurance - and this is when a very large portion of wealth is at risk. Although this model is overly simple, it makes plain that for catastrophic risks that require high multipliers, failing to purchase insurance or underinsuring may be a rational consumer response. While a great deal of literature lays the blame for failing catastrophe insurance markets on the irrationality of those at risk, this simple analysis suggests that that may not be the case. The extra loading required to cover catastrophic lines can be substantial since for these types of risks, bundling policies does not offer the benefits it does for thin-tailed and independent loss distributions. In some cases, therefore, insurance does not provide enough of a benefit to homeowners to pay the required loadings, or becomes too expensive as homeowners bump against their budget constraint. In these situations, no amount of homeowner education or outreach activities will increase demand.

Of course, the situation will be exacerbated by the well-documented biases individuals exhibit when evaluating low-probability risks. ${ }^{32}$ In the simple model presented here, homeowners are assumed to know the probability and loss they face with certainty. In reality, these are often unknown and in forming subjective assessments about low-probability risks, homeowners have been found to exhibit a set of biases, such as treating low-probability risks as zero-probability and being overly optimistic about losses. ${ }^{33}$ For fat-tailed risks, homeowners could also be estimating expected loss based on only a few years of their past experience. If these were years with low losses, it will lead them to incorrectly believe that premiums should be low. There is already a documented bias towards individuals assuming that small samples are representative ${ }^{34}$; the impact of this will be even more pernicious with fat tails. These types of biases can lead to sub-optimally low levels of insurance, but the simple model here suggests that a bigger problem may simply be the inherent difficulty in insuring catastrophic risks due to the required loadings.

Our simple model agrees with one empirical study that the price elasticity of catastrophe insurance is much greater than for non-catastrophe insurance. ${ }^{35}$ Empirical estimates of the price elasticity for disaster insurance are difficult, however, since risk and price are positively correlated. Athavale and Avila ${ }^{29}$ address this with a twoequation model for earthquake insurance in Missouri and find that once the impact of risk on price is accounted for, demand is inelastic with respect to price. This is a region with no recent extreme earthquakes and not a huge variation in price apart from risk. As the authors note, low demand could be also be influenced by expectations of relief for catastrophic events, although empirical evidence on this is limited. Theoretically,

\footnotetext{
${ }^{32}$ For example, Kahneman et al. (1982).

${ }^{33}$ For example, Camerer and Kunreuther (1989).

34 Tversky and Kahneman (1982).

${ }^{35}$ Grace et al. (2004).
} 
the effect of an increase in the price of insurance on demand depends on the individual's level of risk aversion. If absolute risk aversion increases or is constant with an increase in wealth, then demand decreases when the price of insurance increases.

Our model has examined the homeowner's decision to insure, assuming that their decision does not influence the premiums of the insurer. We assume that the insurer knows how additional policies in a given region or line will impact the tail risk of their loss distribution (potentially estimated with catastrophe models) and prices policies accordingly. When catastrophes occur infrequently, though, it can be difficult to get a good estimate of the tail of the loss distribution. And we have seen that correlations below a threshold of statistical significance can still be problematic. It is thus possible for an insurer to not be aware of the nature of the tail of their aggregate loss distribution and thus not manage the risk appropriately. Sometimes an extreme event may convince an insurer that they have been mis-estimating a catastrophic risk and they may then seek to adjust their pricing or the amount of insurance written. This was seen, for instance, after Hurricane Katrina along the Gulf Coast. These adjustments, however, can be limited by state regulatory constraints, ${ }^{36}$ some of which were discussed above.

\section{Policy implications}

We have shown that catastrophic loss distributions can require premiums that may be greater than homeowners are willing to pay. That is, given the necessarily high premiums, it may be quite rational to not buy catastrophe insurance. Insurance, however, can generate positive externalities. Uninsured homeowners are often given federal disaster relief, paid for by all taxpayers, and insurance can reduce the need for this aid. ${ }^{37}$ Insured home- and business-owners are more likely to have the funds to rebuild and to do so quickly, generating economic spillover effects in the community. As homeowners do not consider the benefits to neighbours of insuring, too few people may insure, suggesting that if insurance could be provided more cheaply for these risks without threatening the solvency of insurers, it could provide both private and public benefits.

The necessary multipliers for catastrophe insurance can, of course, be decreased somewhat with appropriate diversification. Some companies will rely heavily on diversifying across regions and lines of business, others will use reinsurance to transfer risk, and still others may choose to create subsidiaries in high-risk areas to wall off the rest of the firm from exposure to a particular risk. Diversification strategy is related to

\footnotetext{
${ }^{36}$ Born and Klimaszewski-Blettner (2009).

${ }^{37}$ The interaction between relief and insurance is an important topic but one beyond the scope of this paper. Currently, some forms of disaster relief are not available to homeowners that could have insured, in order to help create an incentive for insurance. Still, it is likely that significant aid goes to those homeowners without insurance or who are under-insured and this would be reduced if insurance penetration increased. There has also been research on the political nature of relief payments (e.g. Garrett and Sobel, 2003; Michel-Kerjan and Wise, 2011); how this is influenced by take-up of private insurance is worthy of further study.
} 
many things beyond management of catastrophe risk, such as efficiency gains, managerial incentives and ownership structure. Diversification across product lines and geographic regions can improve management of catastrophe risk if done appropriately, but will also interact to have a complex relationship on firm productivity. ${ }^{38}$ Discussion of firm trade-offs in determining how much to diversify and in what manner is beyond the scope of this paper. Our findings simply caution against simple assumptions that policies or lines of business are not correlated, since low correlations can still be critical, and suggest that attention be paid to estimating possible tail dependence and the thickness of the tail of aggregate loss distributions as decisions are made about where to increase holdings. ${ }^{39}$

It may be worth noting that, potentially problematically for reinsurance and broad geographical diversification, tail dependence has been found between equity returns across insurance markets in different regions of the world. Sheremet and Lucas ${ }^{40}$ estimate that for Europe-America and Europe-Australia/Asia, about 60 per cent of the dependence is due to correlated losses, as opposed to correlation in investment portfolios. The percentage is higher for America-Australia/Asia. The authors also find some evidence to suggest that dependence is increasing over time, potentially from climate change. This could be one of the causes of the low levels of reinsurance and high prices that have been documented for catastrophe risks. ${ }^{41}$ Interestingly, the authors find far less correlation between American and Australian-Asian markets, suggesting some areas where diversification can still occur. ${ }^{40}$ Still, if large losses are tending to be correlated across the globe, this will fundamentally undermine the ability of (re)insurers to diversify natural disaster risk.

One potential policy response is to make it cheaper for insurance companies to build and access surplus. A mechanism to do this is allowing for tax-deferred catastrophe reserves. ${ }^{42}$ Currently, insurance companies must keep catastrophe funds in general surplus accounts where they may be depleted, regulators may treat the extra funds as reasons for more stringent price regulations, and additional surplus and the investment earnings on it are taxed as income. ${ }^{20}$ To help overcome this problem, insurers could choose to allocate catastrophe funds to a trust or separate account where they could accumulate tax free, and only be withdrawn for payment of claims following predefined triggers. ${ }^{43}$

Another approach to address high loss layers is for the federal government to act as a reinsurer for catastrophic lines. The government can always provide (re)insurance more cheaply than the private sector since it would not need extra loadings to cover the cost of capital and need not adhere to strict solvency constraints since it can borrow intertemporally. It has been shown that public insurance programmes in other

\footnotetext{
38 Elango et al. (2008).

${ }^{39}$ Beyond diversification, the ability of insurers to cover catastrophic lines depends on aspects of the firm, such as ownership structure, profitability, size, leverage and its tax position (Kleffner and Doherty, 1996), and our simple model does not address those issues.

${ }^{40}$ Sheremet and Lucas (2008).

${ }^{41}$ Froot (2001) and Froot (2008).

${ }^{42}$ Harrington and Niehaus (2001) and Milidonis and Grace (2007).

43 Davidson (1998).
} 
countries have very low operating expenses and these savings can be passed on to customers. ${ }^{44}$ Lewis and Murdock ${ }^{45}$ have argued for federal excess-of-loss contracts for very high layers of coverage. The authors suggest industry-wide triggers to minimise moral hazard. Litan $^{46}$ proposes a pre-funded programme administered by a quasiindependent group in the Treasury Department to provide reinsurance to insurance companies or state plans. Premiums would be risk-based and could be reduced if the entity adopted risk reduction measures. Government would only cover losses above a relatively high threshold, with lower level losses being covered by private insurance and state and local governments. This layered approach, it is argued, will provide incentives for all parties to adopt mitigation measures. Cutler and Zeckhauser ${ }^{47}$ note that federal reinsurance could allow private market functioning for smaller losses, internalise some loss costs that the government has control over and raise revenues for a service the government may provide anyway.

While government (re)insurance could likely bring down the cost of disaster insurance, this would have to be carefully balanced against three potential problems. The first is the potential to push private (re)insurers out of the market. However, if limited to truly catastrophic layers and designed carefully, it is possible that the programme would help private companies limit their exposure and provide coverage for lower loss layers. The second is that the lower price offered for catastrophe insurance, while potentially increasing take-up rates, could introduce moral hazard problems. If moral hazard was a significant problem, the public intervention could perversely increase exposure. It may be possible to control moral hazard through heavy state investment in mitigation. More empirical research is needed on how severe of a moral hazard problem has been generated by government interventions in catastrophe insurance to date and what politically feasible mechanisms are successful in limiting it. Finally, with public-private programmes, all high-risk losses being pushed to the public sector could undermine the financial viability of the public programme. ${ }^{48}$ Some of the methods around this, such being used by the Florida Hurricane Catastrophe Fund - assessing fees on captive policyholders ex post-have been challenged on grounds of equity and moral hazard.

We believe that the biggest priority for addressing catastrophic risks should be mitigation. With national mapping of structures and populations, governments can target intervention to encourage mitigation at "hot spots" through the use of catastrophe modelling, as suggested by Muir-Wood. ${ }^{49}$ The government should prefer to lower damage costs as this would reduce ex post aid, minimise the economic impacts of disasters and reduce pain and suffering. Homeowners, too, given the uninsurable costs of a disaster, should prefer, for a range of costs, to protect their home against damage rather than face a risk of disaster and insure. Indeed, there is evidence to suggest that in high-risk areas, homes built under stronger building codes

\footnotetext{
44 von Ungern-Sternberg (2004).

${ }^{45}$ Lewis and Murdock (1996).

${ }^{46}$ Litan (2006).

47 Cutler and Zeckhauser (1999).

${ }^{48}$ For more discussion on this topic, see Jametti and von Ungern-Sternberg (2010).

${ }^{49}$ Muir-Wood (2011).
} 
command a price premium ${ }^{50}$ and a study of residents in and outside New Orleans found both groups willing to pay for public flood protection projects. ${ }^{51}$ Many mitigation measures have proven to be cost-effective, paying for themselves in reasonable time frames. Far fewer homes are fortified against disasters, however, than this would suggest. Partly, this is because insurers do not promote or encourage mitigation (a few state laws forcing premium reductions for mitigation are an exception). Homeowners may fail to mitigate for a variety of other reasons: they underestimate or dismiss the probability of a disaster, are myopic, do not see or understand the mitigation in place when purchasing a home, do not have the necessary upfront costs, do not consider the benefits to their neighbours, and/or are not as concerned about disaster losses due to federal aid. ${ }^{52}$ Creative solutions for overcoming these barriers would provide public benefits.

\section{Conclusion}

Insuring risks with loss distributions characterised by fat tails and dependence is expensive. These costs are passed on to consumers in the form of higher loadings on catastrophic lines. Given this, we have shown in a very simple model that, in a range of cases, it may be rational for consumers to forego catastrophe insurance. Since such insurance may provide public benefits, however, there may be social benefits in helping consumers manage the catastrophic risks they face, such as through incentives for mitigation or policy structures that lower the costs to insurers of bearing catastrophic risks. Future work should explore these findings in a more nuanced model of the insurance market.

\section{Acknowledgement}

This work was made possible by NSF grant \#SES-0960865.

\section{References}

Athavale, M. and Avila, S.M. (2011) 'An analysis of the demand for earthquake insurance', Journal of Risk and Insurance 14(2): 233-246.

Born, P.H. and Klimaszewski-Blettner, B. (2009) Catastrophes and Performance in Property Insurance: A Comparison of Personal and Commercial Lines, Oakland, CA: The Independent Institute.

Camerer, C.F. and Kunreuther, H. (1989) 'Decision processes for low probability events: Policy implications', Journal of Policy Analysis and Management 8(4): 565-592.

Cleeton, D.L. and Zellner, B.B. (1993) 'Income, risk aversion, and the demand for insurance', Southern Economic Journal 60(1): 146-156.

Cooke, R. and Kousky, C. (2010) 'The limits of securitisation: Micro-correlations, fat tails, and tail dependence', in K. Bocker (ed.) Rethinking Risk Measurement and Reporting Volume I: Uncertainty, Bayesian Analysis, and Expert Judgement, London: Risk Books, pp. 273-294.

Cooke, R.M. and Nieboer, D. (2011) Heavy-Tailed Distributions: Data, Diagnostics, and New Developments, Washington, DC: Resources for the Future.

\footnotetext{
${ }^{50}$ Dumm et al. (2011).

51 Landry et al. (2011).

${ }^{52}$ Lewis and Murdock (1999) and Kunreuther (2006).
} 
Cutler, D.M. and Zeckhauser, R.J. (1999) ‘Reinsurance for catastrophes and cataclysms', in K.A. Froot (ed.) The Financing of Catastrophe Risk, Chicago, IL: University of Chicago Press, pp. 233-269.

Davidson, R.J.J. (1998) 'Working toward a comprehensive national strategy for funding catastrophe exposure', Journal of Insurance Regulation 17(2): 134-170.

Dixon, L., Clancy, N., Seabury, S.A. and Overton, A. (2006) The National Flood Insurance Program's Market Penetration Rate: Estimates and Policy Implications, Santa Monica, CA: RAND Corporation.

Dumm, R., Sirmans, G. and Smersh, G. (2011) 'The capitalization of building codes in house prices', The Journal of Real Estate Finance and Economics 42(1): 30-50.

Elango, B., Ma, Y.-L. and Pope, N. (2008) 'An investigation into the diversification-performance relationship in the U.S. property-liability insurance industry', The Journal of Risk and Insurance 75(3): 567-591.

Froot, K.A. (2001) 'The market for catastrophe risk: A clinical examination', Journal of Financial Economics 60(2/3): 529-571.

Froot, K.A. (2008) 'The intermediation of financial risks: Evolution in the catastrophe reinsurance market', Risk Management and Insurance Review 11(2): 281-294.

Garrett, T.A. and Sobel, R.S. (2003) 'The political economy of FEMA disaster payments', Economic Inquiry 41(3): 496-508.

Grace, M.F., Klein, R.W. and Kleindorfer, P.R. (2004) 'Homeowners insurance with bundled catastrophe coverage', The Journal of Risk and Insurance 71(3): 351-379.

Harrington, S.E. and Niehaus, G. (2001) 'Government insurance, tax policy, and the affordability of catastrophe insurance', Journal of Insurance Regulation 19(4): 591-612.

Holmes, T.P., Huggett Jr., R.J. and Westerling, A.L. (2008) 'Statistical analysis of large wildfires', in T.P. Holmes, J.P. Prestemon and K.L. Abt (eds.) The Economics of Forest Disturbances: Wildfires, Storms, and Invasive Species, New York, Springer Science, pp. 59-77.

Ibragimov, R., Jaffee, D. and Walden, J. (2009) 'Nondiversification traps in catastrophe insurance markets', The Review of Financial Studies 22(3): 959-993.

Jaffee, D.M. and Russell, T. (1997) 'Catastrophe insurance, capital markets, and uninsurable risks', The Journal of Risk and Insurance 64(2): 205-230.

Jametti, M. and von Ungern-Sternberg, T. (2010) 'Risk selection in natural-disaster insurance', Journal of Institutional and Theoretical Economics 166(2): 344-364.

Johnson, E.J., Hershey, J., Meszaros, J. and Kunreuther, H. (1993) 'Framing, probability distortions, and insurance decisions', Journal of Risk and Uncertainty 7(1): 35-51.

Kahneman, D., Slovic, P. and Tversky, A. (eds.) (1982) Judgment Under Uncertainty: Heuristics and Biases, Cambridge, UK: Cambridge University Press.

Kleffner, A.E. and Doherty, N.A. (1996) 'Costly risk bearing and the supply of catastrophic insurance', The Journal of Risk and Insurance 63(4): 657-671.

Klein, R.W. (2005) A Regulator's Introduction to the Insurance Industry, Kansas City, MO: National Association of Insurance Commissioners.

Klein, R.W. and Wang, S. (2007) Catastrophe Risk Financing in the US and EU: A Comparative Analysis of Alternative Regulatory Approaches, SCOR-JRI Conference on Insurance, Reinsurance and Capital Market Transformations. Paris, France. 20-21 September.

Kleindorfer, P.R. and Klein, R.W. (2002) 'Regulation and markets for catastrophe insurance', in M.R. Sertel and S. Koray (eds.) Advances in Economic Design, Berlin: Springer-Verlag, pp. 263-280.

Kousky, C. (2011) 'Managing the risk of natural catastrophes: The role and functioning of state insurance programs', Review of Environmental Economics and Policy 5(1): 153-171.

Kunreuther, H. (1996) 'Mitigating disaster losses through insurance', Journal of Risk and Uncertainty 12(2): 171-187.

Kunreuther, H. (2006) 'Disaster mitigation and insurance: Learning from Katrina', The ANNALS of the American Academy of Political and Social Science 604(1): 208-227.

Kunreuther, H. and Pauly, M. (2004) 'Neglecting disaster: Why don't people insure against large losses?' Journal of Risk and Uncertainty 28(1): 5-21.

Kunreuther, H., Michel-Kerjan, E., Doherty, N.A., Grace, M.F., Klein, R. and Pauly, M. (eds.) (2009) At War with the Weather: Managing Large-Scale Risks in a New Era of Catastrophes, Cambridge, MA: MIT Press. 
Kurowicka, D. and Cooke, R. (2006) Uncertainty Analysis with High Dimensional Dependence Modelling, West Sussex, England: John Wiley \& Sons, Ltd.

Kurowicka, D. and Joe, H. (2011) Dependence Modeling: Vine Copula Handbook, Singapore: World Scientific Publishing.

Ladoucette, S.A. and Teugels, J.L. (2006) 'Analysis of risk measures for reinsurance layers', Insurance: Mathematics and Economics 38(3): 630-639.

Landry, C.E., Hindsley, P., Bin, O., Kruse, J.B., Whitehead, J.C. and Wilson, K. (2011) 'Weathering the storm: Measuring household willingness-to-pay for risk-reduction in post-Katrina New Orleans', available from SSRN: http://ssrn.com/abstract $=1824426$.

Lescourret, L. and Robert, C.Y. (2006) 'Extreme dependence of multivariate catastrophic losses', Scandinavian Actuarial Journal 4: 203-225.

Lewis, C.M. and Murdock, K.C. (1996) 'The role of government contracts in discretionary reinsurance markets for natural disasters', The Journal of Risk and Insurance 63(4): 567-597.

Lewis, C.M. and Murdock, K.C. (1999) 'Alternate means of redistributing catastrophic risk in a national risk-management system', in K.A. Froot (ed.) The Financing of Catastrophe Risk, Chicago, IL: University of Chicago Press, pp. 51-85.

Litan, R.E. (2006) Sharing and Reducing the Financial Risks of Future 'Mega-Catastrophes'. Issues in Economic Policy, Washington, DC: The Brookings Institution.

Michel-Kerjan, E. and Wise, J.V. (2011) The risk of ever-growing disaster relief expectations, Prepared for the NBER Insurance Group Workshop. Cambridge, MA. September.

Milidonis, A. and Grace, M.F. (2007) Tax-deductible pre-event catastrophe loss reserves: The case of Florida, Working Paper, The University of Manchester, Manchester, UK.

Mossin, J. (1968) 'Aspects of rational insurance purchasing', The Journal of Political Economy 76(4): $553-568$.

Muir-Wood, R. (2011) Designing optimal risk mitigation and risk transfer mechanisms to improve the management of earthquake risk in Chile, OECD Working Papers on Finance, Insurance and Private Pensions, No. 12, OECD Publishing, from http://dx.doi.org/10.1787/5kg26lpfxcr5-en.

Nelson, R. (1999) An Introduction to Copulas, New York: Springer.

Newman, M.E.J. (2005) 'Power laws, Pareto distributions and Zipf's law', Contemporary Physics 46(5): 323-351.

Palm, R. (1995) 'The Roepke lecture in economic geography-Catastrophic earthquake insurance: Patterns of adoption', Economic Geography 71(2): 119-131.

Powell, E.A. (2006) 'Few Americans sign up for earthquake insurance despite potential for huge losses, report says', Associated Press, 16 October.

Rees, R. and Wambach, A. (2008) 'Microeconomics of insurance', Foundations and Trends in Microeconomics 4(1-2): 1-163.

Resnick, S. (2007) Heavy Tailed Phenomena: Probabilistic and Statistical Modeling, New York: Springer.

Schoenberg, F.P., Peng, R. and Woods, J. (2003) 'On the distribution of wildfire sizes', Environmetrics 14(6): 583-592.

Sheremet, O. and Lucas, A. (2008) Global loss diversification in the insurance sector, Tinbergen Institute Discussion Paper, Tinbergen Institute, Amsterdam, The Netherlands.

Tversky, A. and Kahneman, D. (1982) 'Belief in the law of small numbers', in D. Kahneman, P. Slovic and A. Tversky (eds.) Judgment Under Uncertainty: Heuristics and Biases, Cambridge, UK: Cambridge University Press, pp. 23-31.

von Ungern-Sternberg, T. (2004) Efficient Monopolies: The Limits of Competition in the European Property Insurance Market, Oxford: Oxford University Press.

\section{About the Authors}

Carolyn Kousky is a Fellow at Resources for the Future in Washington DC. Her research focuses on natural resource management, decision-making under uncertainty, and individual and societal responses to natural disaster risk. She has examined how individuals learn about extreme event risk, the demand for natural disaster insurance 
and policy responses to potential changes in extreme events with climate change. She has a B.S. in Earth Systems from Stanford University and a Ph.D. in Public Policy from Harvard University.

Roger Cooke is the Chauncey Starr Senior Fellow at Resources for the Future. His work focuses on methodological issues of risk analysis, uncertainty analysis and expert judgement. He has published four books, edited two books, published 101 articles in international refereed journals and published 115 papers in refereed international conference proceedings and books. In 2011, he received the Lifetime Distinguished Achievement Award from the Society for Risk Analysis. 